\title{
Efficacy of Beta Radiation in Prevention of Post-Angioplasty Restenosis
}

\author{
An Interim Report from the Beta Energy Restenosis Trial \\ David Meerkin $^{1}$, Raoul Bonan ${ }^{1}$, Ian R. Crocker ${ }^{2}$, André Arsenault ${ }^{1}$, Prakash Chougule ${ }^{3}$, \\ Veronique Coen ${ }^{4}$, David O. Williams ${ }^{3}$, Patrick Serruys ${ }^{4}$, Spencer B. King III ${ }^{2}$
}

\begin{abstract}
Restenosis remains a major limitation of coronary angioplasty in spite of major advances in techniques and technology. Recent studies have demonstrated that ionizing radiation may limit the degree of this problem. Gamma radiation has been shown to be elfective in reducing in stent restenosis in humans, and beta radiation following encouraging results in animals has been shown to be feasible in humans. The objective of this study was to assess the feasibility of a $5 \mathrm{~F}$ non-centered catheter to deliver beta radiation emitting seeds to the lesion site post angioplasty and its effect on restenosis. Following successful angioplasty, patients were randomized to treatment with 12.14 or $16 \mathrm{~Gy}$ at the angioplasty site. This was delivered with a $5 \mathrm{~F}$ non-centered catheter. Twelve beta radiation emitting seeds ( ${ }^{\circ} \mathrm{Sr} / \mathrm{Y}$ ) were delivered to an area
\end{abstract}

Key Wurds: Beta Radiation - Restenosis · Coronary angioplasty
$3 \mathrm{~cm}$ in length to cover the angioplasty site. Angiographic fol low-up was performed at 6 months. Baseline and follow-up angiograms were performed by blinded investigators at a core laboratory.

This interim report comprises the first 35 patients to complete 6-month angiographic follow-up. There were no major radiation incidents. Four patients had evidence of angiographic restenosis. The MLD (mm) and percent stenosis were $0.77 \pm$ $0.27 / 72.5 \pm 8.6$ pre angioplasty $2.08 \pm 0.4 / 25.7 \pm 9.8$ post angioplasty and radiation and $2.05 \pm 0.59 / 25.7 \pm 19.8$ at follow-up respectively.

Conclusion: Beta radiation can be feasibly and safely delivered post coronary angioplasty with a very encouraging reduc tion of restenosis.

\section{Wirksamkeit der Betastrahlung zur Prävention der Restenose nach PTCA: Ein Zwischenbericht der BERT-Studie}

Zusammenfassung: Trotz größerer Fortschritte bleibt die Restenose die entscheidende Limitation der PTCA. Kürzlich durchgefuhrte Studien haben gezeigt, daß ionisierende Strahlen das Ausmaß dieses Problems begrenzen können. Gammastrahlung ist zur Reduktion der Instentrestenose auch bei Patienten effektiv, für Bctastrahlen gibt es sowohl in Tieruntersuchungen als auch bei Patienten ermutigende Ergebnisse. Das Ziel dieser Studie war festzustellen, ob die Verwendung eines nicht zentricrten 5 F-Katheters zur Verabreichung von betastrahlenden Zylindern einen Effekt auf die Restenose nach PTCA aufweist.

In AnschluB an eine erfolgreiche PTCA wurden die Patienten zur Behandlung mit 12, 14 oder 16 Gy randomisiert. Zwölf betastrahlende Zylinder (,,seeds") mit ${ }^{90} \mathrm{Sr} / \mathrm{Y}$ wurden über eine Länge von $3 \mathrm{~cm}$ appliziert, um die PTCA-Stelle abzudecken. Die Kontrollangiographie erfolgte nach sechs Monaten. Die Auswertung der Ausgangs- und Kontrollangiogramme wurde entsprechend eines doppelblinden. Protokolls durchgeführt.

Dieser Zwischenbericht umfaßt die ersten 35 Patienten, bei denen die Sechs-Monats-Kontrollangiographie durchgefuhrt wurde. Es gab keine größeren Strahlenunfälle. Bei vier Patienten kam es zu einer angiographisch definierten Restenose. Der minimale Lumendurchmesser (MLD) betrug 0,77 $\pm 0,27 \mathrm{~mm}$ und die Durchmesserstenose $72,5 \pm 8,6 \%$ (vor PTCA), 2,08 $0,4 \mathrm{~mm}$ und $25,7 \pm 9,8 \%$ nach PTCA und Bestrahlung sowie $2,05 \pm 0,59 \mathrm{~mm}$ und $25,7 \pm 19,8 \%$ bei Kontrollangiographie. SchluBfolgerung: Eine Betabestrahlung kann einfach und sicher nach PTCA durchgeführt werden, die Ergebnisse zur Verhinderung der Restenose sind ermutigend.

Schlïsselwörter: Betastrahlung $\cdot$ Restenose $\cdot$ PTCA

\footnotetext{
Institut de Cardiologie de Montréal, Québec, Canada

Emory University, Atlanta, Georgia, USA,

${ }^{3}$ Rhode. Island Hospital, Providence, USA,

"Thoraxcenter, Rotterdam, Netherlands.
} 
$\mathrm{T}$ he application of intracoronary brachytherapy to the problem of post angioplasty restenosis represents a potential solution to what remains a vexing problem. Progress in refinement of technology and improve. ment of techniques have allowed interventional cardiologists to tackle increasingly challenging situations successfully. In spite of this, the multiple attempts to limit the problem of restenosis have met with consistent disappointment [7]. Following numerous encouraging animal studies [1, 15-17], intracoronary gamma radiation has recently been demonstrated to be feasible in humans [3] and in a small, randomized trial to limit the problem of in-stent restenosis [13]. Although numerous beta radiation emitting systems have been used in animal studies, only a single system of a balloon centered 90 -yttrium ( ${ }^{90} \mathrm{Y}$ ) wire for post angioplasty use, has been reported in humans in a small feasibility trial [14].

The objective of the Beta Energy Restenosis Trial (BERT) was to assess the feasibility and safety of 3 prescribed doses of beta radiation delivered post angioplasty to the coronary artery by means of a non-centered 5 French (F) catheter-based system for reducing restenosis in non-stented coronary arteries, and to determine its effect on the restenosis process.

\section{Methods}

In this interim analysis of the multicenter randomized open trial, 14 patients were recruited at Emory University Hospital, 6 at Rhode Island Hospital and 16 at the Institut de Cardiologie de Montreal.

The protocol was approved by the institutional review board of each participating institution. Written informed consent was obtained from each patient prior to enrollment and randomization in the trial.

\section{Selection of Patients}

Patients aged between 18 and 80 years with angina or proven ischemia on laboratory testing due to undergo planned balloon angioplasty treatment of a single coronary lesion in a native coronary artery, were eligible for inclusion in the study. The target lesions were required to have between 60 and $99 \%$ diameter stenosis.

Patients were excluded for 1 . evidence of a myocardial infarction within the 3 days prior to the procedure, 2 . contraindication to aspirin, 3. left ventricular ejection fraction less than $40 \%, 4$. serum creatinine greater than
2.0, 5. anticipated difficulty with follow-up, 6. life threatening coexisting illness, 7 . women of child bearing potential, 8. severe peripheral vascular disease, 9. unprotected left main coronary artery disease, 10 . presence of thrombus, 11 . past chest radiotherapy, 12 . lesion angled $>45$ degrees, 13. intraprocedural angiographic evidence of thrombus, spasm or dissection, 14. unsatisfactory PTCA result requiring stent implantation.

\section{Procedure}

The patients were treated with $325 \mathrm{mg}$ of aspirin, intravenous nitroglycerin and heparin in doses adequate to maintain an activated clotting time of at least 300 seconds throughout the procedure. Baseline coronary angiography was performed and followed by PTCA according to standard clinical practice. Fifteen minutes after a successful PTCA, as determined by residual stenosis of $<50 \%$ and an increase of lumen diameter of $>20 \%$, patients were randomized to receive 12,14 , or $16 \mathrm{~Gy}$ as calculated at $2 \mathrm{~mm}$ from the center line. Procedural success was determined by angiography. A $5 \mathrm{~F}$ delivery catheter (Novoste Corp, Norcross, Georgia) was positioned at the site of PTCA with 2 markers separated by $3 \mathrm{~cm}$ used for positioning of the catheter across the angioplasty site (Figure 1). The guidewire was removed and a $3 \mathrm{~cm}$ long train of 90 strontium/yttrium ( ${ }^{90} \mathrm{SR} / \mathrm{Y}$ ) seeds was positioned between the aforementioned markers using fluoroscopic visualization. The seeds remained in place for the period determined to deliver the prescribed dose at $2 \mathrm{~mm}$ from the luminal center line without regard to any curvature of the source train (Figure 2). Following irradiation, angiography was repeated. All cineangiograms were performed following intracoronary nitroglycerin.

Two to 4 hours after the procedure the femoral sheaths were removed. Electrocardiograms were performed immediately and the next morning. Creatine kinase and MB fraction were measured prior to the procedure, at its completion and 8 and 16 hours post procedure. If the procedure was uncomplicated, patients were discharged the next day with instructions to continue $325 \mathrm{mg}$ aspirin indefinitely, and if a stent was implanted, ticlopidine $250 \mathrm{mg}$ twice daily for 15 days.

\section{Radiation Details}

The radiation system used in this study consisted of a series of 12 independent cylindrical seeds delivered as a train in a non-centered delivery catheter. Each seed of 


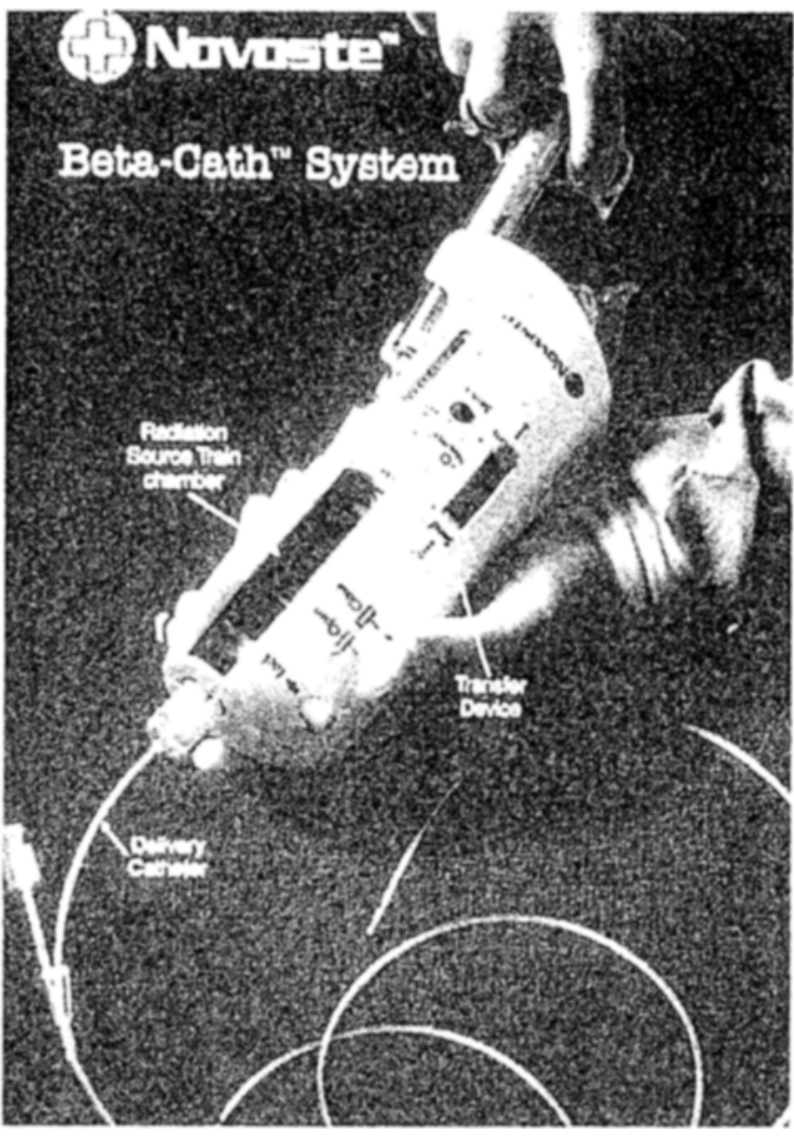

Figure 1. The Novoste ${ }^{T M}$ Beta Cath systern: transfer device attached to the $5 \mathrm{~F}$ catheter

Abbildung 1. Das Novosterm BetaCath-System. Das Transportgehäuse und der 5 F-Katheter.
$2.5 \mathrm{~mm}$ length is composed of radioactive materials $\left({ }^{90} \mathrm{Sr} / 90 \mathrm{Y}\right)$ sintered into ceramic, sealed within a cylindrical stainless steel capsule. The length of the source train chosen was calculated for treatment over $30 \mathrm{~mm}$, allowing for $5 \mathrm{~mm}$ proximal and distal to the angioplasty site when using a standard $20 \mathrm{~mm}$ balloon. The prescribed doses of 12,14 , and $16 \mathrm{~Gy}$ at $2 \mathrm{~mm}$ from the center of the catheter resulted in intracoronary dwell times of 158 to 218 seconds based on source activity and GafChromic Dosimetry Media measurements as previously described [6]. The delivery system is a non-centered $5 \mathrm{~F}$ device with potential for variation from the prescribed radiation dose to that delivered to different sites of the arterial wall. The delivery catheter is non-occlusive in the target coronary vessel and therefore no dose fractionation is necessary or recommended.

\section{Quantitative Angiographic Analysis}

Angiography was performed in 2 orthogonal projections pre and post angioplasty. These same views were repeated following radiation therapy and at follow-up. Decisions regarding inclusion and procedural success were made using an online quantitative angiographic system. All procedural and follow-up angiograms were forwarded to the Emory University Angiographic Core Laboratory for interpretation and measurement by independent observers according to a previously validated method [8] providing diameter of the reference vessel and the minimal lumen diameter (MLD) at basc-

\section{Pre-Treatment}

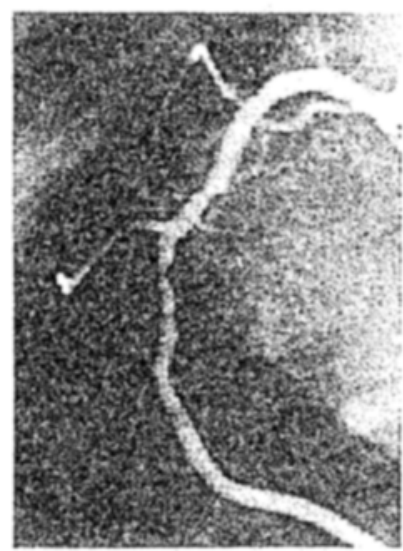

$\beta$ Cath.

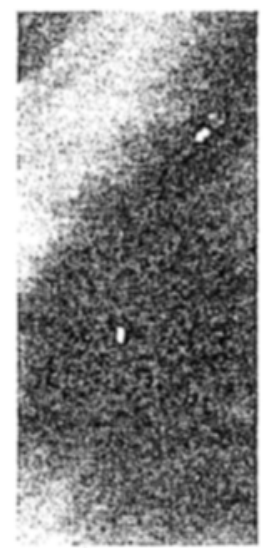

Post-Irradiation

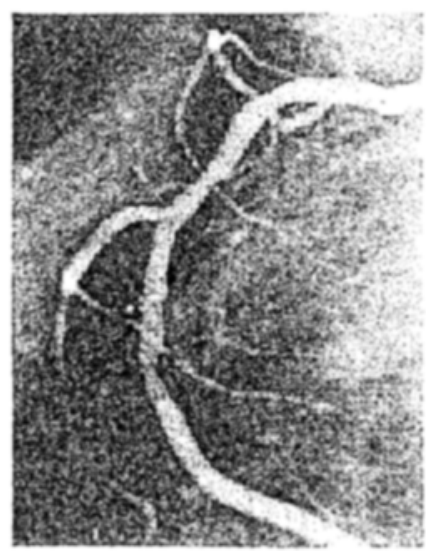

$6 \mathrm{~m} . \mathrm{F}-\mathrm{U}$

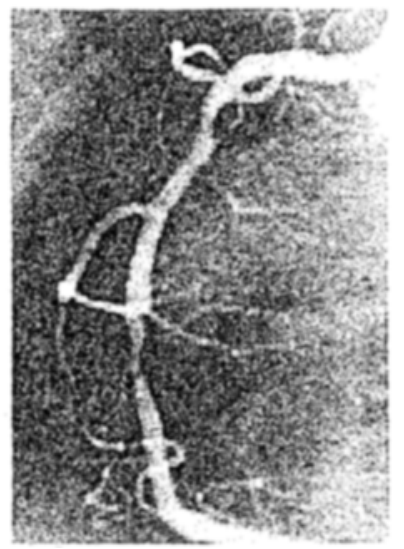

Figure 2. Right coronary artery in RAO projection, pre treatment, with radioactive seeds in place, post treatment result and 6-month follow-tlp showing no evidence of restenosis but some disease progression in an asymptomatic patient witl negative functional tests.

Abbildung 2. Rechte Koronararterie in RAO-Projektion, vor der Behandlung mit den plazierten sadicaktiven Quellen, nach Behandlung und Kontrollangiographie nach sechs Monaten ohne Anhalt fur Restenose bei geringer Progression. Der Patient war asymptomatisch, die nichtinvasiven Befunde unauffälig. 
line, post procedure and at follow-up. Acute gain (mm) was defined as MLD post angioplasty less the MLD pre angioplasty. Late loss was defined as MLD post angioplasty less MLD at follow-up. Loss index was defined as late loss divided by the acute gain. Restenosis was defined as $>50 \%$ diameter stenosis at follow-up.

\section{Follow-Up}

Patients were contacted by telephone monthly. Clinical assessment was performed 3-monthly. Angiographic follow-up was performed at 6 months. Follow-up angiography recorded less than 5 months after the procedure was excluded unless restenosis had occurred.

The primary endpoint was the technical success of the irradiation treatment as defined by the ability to pass the closed end $5 \mathrm{~F}$ radiation catheter to the lesion site as verified by fluoroscopy and recorded on film, the ability to transfer the radiation source to the distal end of the delivery catheter and return it to the transfer device.

Secondary clinical endpoints were death, myocardial infarction, coronary bypass surgery, target lesion revascularization and restenosis as defined by MLD $<50 \%$ at follow-up.

\section{Statistical Analysis}

All values are provided as proportions or as mean + standard deviation. Comparisons of post procedural with 6-month follow-up results were done using the paired $\mathrm{t}$-test. Statistical significance was indicated by $\mathrm{p}$ $<0.05$ on a 2 -tailed test.

\section{Results}

Of 43 patients recruited for inclusion in the study between January 1996 and April 1997. Five patients were excluded following unsatisfactory results with angioplasty alone, requiring stent implantation. Thirty-eight underwent randomization for radiation therapy. One patient was unavailable for follow-up and therefore was excluded from this interim analysis. The radiation catheter and seeds were deployed and the prescribed dose delivered to all but 2 patients. In 1 paticnt, due to severe vascular tortuosity, the delivery catheter could not be advanced to the lesion site. In the other, due to obstruction of the delivery catheter the radioactive seeds could not be transferred in the catheter. The patients' baseline clinical characteristics are shown in Table 1.

\section{Procedure and Early Clinical Outcome}

This interim analysis includes the first 35 patients who underwent successful angioplasty, radiation therapy and 6-month follow-up (Table 2).

The radiation therapy was well tolerated by all the patients with no major complications during the treatments. None of the treatments required fractionation nor were they interrupted prematurely. In a single pati-

\begin{tabular}{ll}
\hline Patients $(\mathrm{n})$ & 35 \\
Age $(\mathrm{y})$ & $58.0(3+-80)$ \\
Diabetes $(\%)$ & $4(11)$ \\
Hyperlipidemia $(\%)$ & $15(42.9)$ \\
Hypertension $(\%)$ & $11(31.5)$ \\
Smoker & $25(71.4)$ \\
\hline
\end{tabular}

Table 1. Patient baseline clinical characteristics.

Tabelle 1. Klinische Ausgangswerte der Patienten.

\begin{tabular}{lll}
\hline Patients & (n) & 35 \\
\hline Vessel & LAD (\%) & $15(42.9)$ \\
& LCx (\%) & $8(22.9)$ \\
& RCA (\%) & $12(34.3)$ \\
LVEF & & $56 \pm 8.8(40-76)$ \\
Lesion type & A (\%) & $6(17.1)$ \\
& B1(\%) & $9(25.7)$ \\
& B2 (\%) & $18(51.5)$ \\
& C (\%) & $2(5.7)$ \\
Calcification & None (\%) & $26(74.3)$ \\
& Mild (\%) & $6(17.1)$ \\
& Moderate $(\%)$ & $2(5.7)$ \\
& Severe $(\%)$ & $1(2.9)$ \\
QCA & Pre treatment & Post treatment \\
MLD (mm) & $0.77 \pm 0.27$ & $2.08 \pm 0.40$ \\
RD (mm) & $2.78 \pm 0.39$ & $2.50 \pm 0.40$ \\
Stenosis (\%) & $72.5 \pm 8.6$ & $25.7 \pm 9.8$ \\
Acute gain (mm) & & $1.31 \pm 0.39$ \\
\hline
\end{tabular}

Table 2. Baseline and post treatment angiographic characteristics ( $L A D=$ left anterior descending; $L C x=$ left circumflex; $R C A=$ right coronary artery; $\mathrm{LVEF}=$ lent ventricular ejection fraction; $\mathrm{OCA}=$ quantitative coronary angiography; MLD = minimal luminal diameter; $\mathrm{RD}=$ reference vessel diameter; acute gain = MLD post treatment minus MLD pre treatment).

Tabelle 2. Angiographische Charakteristika vor und nach Behandlung (LAD $=$ Ramus interventricularis anterior; $L C x=$ Ramus circumflexus; $\mathrm{RCA}=$ rechte Koronararterie; $\mathrm{LVEF}=$ linksventrikuläre Auswurffraktion; QCA = quantitative Koronarangiographie; MLD = minimalet Lumendurchmesser; RD $=$ Durchmesser des ReferenzgefäBes; acute gain = MLD nach PTCA minus $M L D$ vor PTCA). 
ent, due to severe calcification, the delivery catheter could not cover the entire lesion. In another patient, following overtightening of the Tuohy-Borst valve, a kink in the hydraulic system used for sced deployment, prevented the return of the seeds to the protective housing. The entire system was immediately removed and deposited into the awaiting Lucite radioprotective box with no increased radiation exposure. In a further patient the distal gold marker was not retrieved into the protective housing at the completion of the procedure. All the radioactive seeds, however, were safely in the radioprotective housing. There were no acute radiation events.

Following angioplasty and radiation therapy 3 patients suffered acute vessel closure, requiring re-PTCA and stent implantation. Two further patients required stent implantation due to worsening of dissections that were present post PTCA but pre-radiation therapy.

\section{Clinical and Angiographic Follow-Up}

The MLD (mm) and percent stenosis were $0.77 \pm$ $0.27 / 72.5 \pm 8.6$ pre angioplasty, $2.08 \pm 0.4 / 25.7 \pm 9.8$ post angioplasty and radiation and $2.05 \pm 0.59 / 25.7 \pm 19.8$ at follow-up respectively (Table 3 ).

Four of the 35 patient cohort presented with angiographic restenosis at the treated site. PTCA was performed in 1 case for angiographic restenosis at the same site. Two patients underwent coronary artery bypass surgery, one at 4 months although the target lesion had been stented and was patent.

Of the 5 patients treated with stents initially none showed angiographic restenosis, the patients with angiographic restenosis were from the non-stented cohort.

\begin{tabular}{lll}
\hline & Post treatment & 6-month foliow-up \\
\hline MLD $(\mathrm{mm})$ & $2.08 \pm 0.40$ & $2.05 \pm 0.59^{*}$ \\
RD $(\mathrm{mm})$ & $2.80 \pm 0.40$ & $2.77 \pm 0.35^{*}$ \\
Stenosis $(\%)$ & $25.7 \pm 9.8$ & $25.7 \pm 19.8^{*}$ \\
Late loss $(\mathrm{mm})$ & & $0.03 \pm 0.57$ \\
Loss index & & $-0.03 \pm 0.52$ \\
Restenosis $(\%)$ & & $4 / 35(11.4)$ \\
\hline
\end{tabular}

Table 3. Angiographic results at 6 months ( $\mathrm{F}=$ not significant; MLD = minimal luminal diameter; $\mathrm{RD}=$ reference diameter; Late loss = MLD irmediately post treatment minus MLD at follow-up; Loss index $=$ luminal loss [over 6 months] divided by the acute angioplasty gain).

Tabelle 3. Angiographische Ergebnisse nach sechs Monaten.
There were no deaths or myocardial infarctions. No aneurysms were detected angiographically.

\section{Discussion}

The introduction of intracoronary brachytherapy as a potential solution for restenosis has led to encouragement in an otherwise disappointing field. Following probucol [11], it is only the second treatment that appears to reduce the post PTCA restenosis rate, and as opposed to probucol, it requires no pretreatment. Gamma and beta radiation have been shown to be effective in reducing the proliferative component of stenosis in the animal overstretch balloon injury model, and have been demonstrated to be feasibly delivered in humans. A recent randomized controlled trial demonstrated the effectiveness of gamma radiation in reducing in-stent restenosis at 6 months [13]. The single published trial using beta radiation demonstrated feasibility of the approach using a balloon centered ${ }^{\circ} \mathrm{Y}$ wire, however, restenosis occurred in 6 of 15 patients [14].

This interim report of the multicenter BERT study demonstrates the feasibility and short-term safety of applying beta radiation using a non-centered $5 \mathrm{~F}$ delivery catheter, for the prevention of restenosis. In spite of 2 minor catheter incidents, no serious radiation events occurred in the short to medium term. The maintenance of the acute gain over the follow-up period, with minimal late loss and a relatively low angiographic restenosis rate are indicative of the potential for this technique and dispel some of the reservations regarding the effectiveness of beta radiation due to its reduced penetrance and to the treatment timing [12]. This is supported by the low requirement for target lesion and vessel revascularization.

The theoretical concern of radiation catheter edge restenosis due to lower doses causing increased proliferation was not manifest in this study. At the prescribed doses no aneurysms were evident as have been reported with the use of a non-centered gamma radiation system using higher doses [3].

The ${ }^{4} \mathrm{Sr} / \mathrm{Y}$ isotope combination with its prolonged half life of 28 years [6], allows for the use of the same source seeds over a prolonged period and limits the amount of source transfers required resulting in an overall decreased personnel radiation risk. 


\section{Limitations of the Study}

This study represents an interim report of the larger BERT feasibility study and therefore is not powered adequately to provide significant results regarding restenosis and revascularization requirement. It is also a non-controlled study limiting the application of the restenosis results. The follow-up provides important data regarding short to intermediate term complications, however, this must be viewed in the light that significantly higher doses of radiation applied to larger tissue areas, when used for treatment of neoplasms, resulted in an increased risk of coronary artery disease over the much longer term of 5 to 20 years [4]. In spite of this, the safety of brachytherapy when used for keloid $[2,9]$ and heterotopic bone formation $[5]$ has been confirmed for periods of longer than 20 years and furthermore the safety of peripheral vasculat brachytherapy has been demonstrated during a 6-year follow-up period [10].

\section{Conclusion}

This interim analysis of the BERT study demonstrates the feasibility and short and medium term safety of this non-centered $5 \mathrm{~F}$ device for delivering beta radiation to the vessel wall post angioplasty. Larger randomized and longer term studies are required to provide the power to conclusively demonstrate that beta radiation is effective in safely reducing restenosis post angioplasty.

\section{References}

1. Carter, A I, Laird JR, Bailey LR, ct al. Effects of endovascular radiation from a beta particle emitting stent in a porcine coronary restenosis moded. Circulation 1996:94:2364-8.

2. Chaudry MR, Akhtar S. Duvalsaint F, et al. Ear lobe keloids, sur gical excision followed by radiation thetapy: a 10-year experience. Ear Nose Throat J 1994;73:779-81

3. Condado JA, Waksman $R$, Gurdiel $O$, et al. Long-term angiographic and clinical outcome after pereutaneous transluninal coro- nary angioplasty and intracoronary radiation therapy in humans. Circulation 1997:96:727-32.

4. Corn BW, Trock BJ, Goodman RL. Irradiation-related ischemic heart disease. J Clin Oncol 1990;8:741-50.

5. Coventry MB, Scanton PW. The use of radiation to discourage ectopic bone: a nine-year study in surgery about the hip. J Bone Joint Surg [Am] 1981;63:201-8.

6. Cross WG, Ing WG, Freedman N. A short atlas of beta-ray spectra. Phys Med Biol 1983;28:1251-60.

7. Dangas G, Fuster V. Management of restenosis after coronary intervention. Am Hear J 1996;132:428-36.

8. Klein JL, Manoukian SV, Vogel RA, et al, for the Lovastatin Restenosis Trial Group. Computerized quantitative coronary arteriography: performance standards and edge detection. Am . Cardiol 1996;77:815-22.

9. Kovalic IJ, Perez CA. Radiation therapy following keloidectomy: a 20-year experience. Int I Radiat Oncol Biol Phys 1989;17:77-80.

10. Schopohl B, Liermana D, Pohlit LJ. 192 Ir endovascular radjation brachytherapy for avoidance of intimal hyperplasia after percutaneous transluminal angioplasty and stent implantation in peripheral vessels: 6 years of experience. Int $J$ Radiat Oncol Biol Phys $1996 ; 36: 835-40$.

11. Tardif J-C, Cote $G$, Lesperance J, et al. Probucol and multivitamins in the prevention of restenosis after coronary angioplasty. Multivitamins and Probucol Study Group. $N$ Engl $J$ Med 1997:337:365-72.

12. Teirstein P. Beta radiation to reduce restenosis. Circulation 1997;95:1095-7.

13. Teirstein PS, Massullo V, Jani S, et al. Catheter-based radiotherapy to inhibit restenosis after coronary stenting. $N$ Engl J Med 1997-336:1697-703.

14. Verin V, Urban P, Popowski Y, et al. Feasibility of intracoronary beta radiation to reduce restenosis after balloon angioplasty. Circulation 1997;95:1138-44.

15. Waksman R, Robinson KA, Crocker IR, et al. Endovascular lowdose irradiation inhibits neointima formation after coronary artery balloon injury in swine. Circulation 1995;91:1533-9.

16. Waksman R, Robinson KA. Crocker IR, et al. Intracoronary lowdose beta -irradiation inhibits neointima formation after coro. nary artery balloon injury in the swine restenosis model. Circulation 1995;92:3025-31

17. Weiderman JG, Marboe $\mathrm{CH}$, Amols $\mathrm{H}$, et al. Intracoronary irradiation markedly reduces restenosis after balloon angioplasty in a porcine model. J Am Coll Cardiol 1994;23:1491-8.

Address for Correspondence: Raoul Bonan, MD, Institu de Cardiologie de Montréal, s0MO est, rue Bélanger, Montréal. Qué, HIT 1 C8, Canada,

Fon (+1/514) 376-3330, Fax -6299,

e-mail:icn33@connectrmmic.net 